\title{
Genotyping of Phytophthora infestans in Eastern Africa Reveals a Dominating Invasive European Lineage
}

\author{
Anne W. Njoroge, ${ }^{1,2}$ Björn Andersson, ${ }^{2}$ Alison K. Lees, ${ }^{3}$ Collins Mutai, ${ }^{4}$ Gregory A. Forbes, ${ }^{5, \dagger}$ \\ Jonathan E. Yuen, ${ }^{2}$ and Roger Pelle ${ }^{4}$ \\ ${ }^{1}$ International Potato Center (CIP), PO Box 25171-00603 Nairobi, Kenya; ${ }^{2}$ Swedish University of Agricultural Sciences, Department of Forest \\ Mycology and Plant Pathology, PO Box 7026, S-750 07 Uppsala, Sweden; ${ }^{3}$ Cell and Molecular Sciences, The James Hutton Institute, Dundee, \\ DD2 5DA, United Kingdom; ${ }^{4}$ Biosciences eastern and central Africa-International Livestock Research Institute Hub, PO Box 30709-00100, \\ Nairobi, Kenya; and ${ }^{5}$ CIP, PO Box 1558 , Lima 12, Peru \\ Accepted for publication 24 September 2018.
}

\begin{abstract}
Strains of Phytophthora infestans, the pathogen causing late blight of potato and tomato, are thought to be moved around the world through infected planting material. Since its first appearance in 1941, late blight has caused important losses to potato production in the eastern-Africa region (EAR). In the current study, the genetic structure of the population in Kenya, Uganda, Tanzania, Burundi, and Rwanda was characterized using 12-plex microsatellite markers with the aim of testing the hypothesis that a strain originating from Europe, 2_A1, has recently dominated the population in EAR. Analyses of 1,093 potato and 165 tomato samples collected between 2013 and

2016 revealed the dominance on potato in all countries of the 2_A1 clonal lineage. On tomato, a host-specialized form of the US-1 lineage appears to persist in Rwanda, Uganda, and Tanzania whereas, in Kenya, most samples from tomato $(72.5 \%)$ were 2_A1. The US-1 lineage in Tanzania had two private alleles at the $\mathrm{Pi} 02$ marker, suggesting a possible independent introduction into the region. US-1 had higher genetic variability than 2_A1, consistent with the earlier establishment of the former. Continuous tracking of $P$. infestans population changes should help identify new virulent and aggressive strains, which would inform strategic disease management options.
\end{abstract}

The oomycete plant pathogen Phytophthora infestans (Mont.) de Bary causes devastating late blight, mainly on potato (Solanum tuberosum L.) and tomato (S. lycopersicum L.); however, the pathogen has a wide host range within the Solanaceae family. $P$. infestans is a heterothallic organism requiring both mating types A1 and A2 for sexual reproduction. In areas where sexual reproduction is absent, asexual clonal populations (lineages) dominate. The disease emerged in the mid-1840s (Berkeley 1846), when it contributed to the Great Famine in Ireland (Zadoks 2008). In eastern Africa, the epidemic which led to the discovery of the pathogen in the region was documented by Dr. Nattrass, who found the disease in Kenya in 1941 on the potato cultivar Kerr's Pink, in a crop that had been planted with imported seed (Natrass 1944). A year after the original outbreak in Kenya, the disease was discovered in eastern Uganda, which borders Kenya. The disease then spread, moving west into the Democratic Republic of Congo and south into Tanzania (Natrass 1944).

The complexity of controlling late blight arises from factors associated with pathogen movement between continents. This has

†Corresponding author: G. A. Forbes; E-mail: gregaforbes@gmail.com

Funding: The laboratory aspects of this work were funded by the Biosciences central and eastern Africa-International Livestock Research Institute (BecA-ILRI) Hub through the Africa Biosciences Challenge Fund (ABCF) program. The ABCF Program is funded by the Australian Department for Foreign Affairs and Trade through the BecA-CSIRO partnership, the Syngenta Foundation for Sustainable Agriculture, the Bill \& Melinda Gates Foundation, the U.K. Department for International Development, and the Swedish International Development Cooperation Agency. The field sampling was undertaken as part of, and funded by, the CGIAR Research Program on Roots, Tubers and Bananas and supported by CGIAR Fund Donors.

*The $\boldsymbol{e}$-Xtra logo stands for "electronic extra" and indicates that one supplementary figure is published online.

The author(s) declare no conflict of interest.

(C) 2019 The American Phytopathological Society resulted in the introduction of strains with novel virulence, increased fitness, and fungicide resistance and of the opposite mating type to the one already present. At the time of the original introduction of $P$. infestans in eastern Africa, a large shipment of potato cultivar Kerr's Pink was imported from the United Kingdom for the 1941 cropping season (Cox and Large 1960). Therefore, it is likely that the original strains of $P$. infestans in eastern Africa resembled those in the United Kingdom at the time.

Strains of $P$. infestans have been monitored using one or more standardized markers, including mating type, fungicide (metalaxyl) resistance (Cardenas et al. 2012), mitochondrial (mt)DNA haplotype, restriction fragment length polymorphisms (RFLPs), analyses with the probe RG-57 (Goodwin et al. 1994), isozymes (glucose-6-phosphatase isomerase [Gpi] and peptidase) (Shattock et al. 1986a; Tooley et al. 1985), amplified fragment length polymorphisms (Cooke et al. 2003; Flier et al. 2003), and, more recently, simple sequence repeats (SSRs) (Knapova and Gisi 2002; Lees et al. 2006; Li et al. 2010). The phenotypic and genotypic data obtained from these markers is subsequently used to describe $P$. infestans multilocus genotypes (MLGs) according to a globally used nomenclature system. The first strain to be isolated and described in the United States was named US-1 (Goodwin et al. 1994) and its designation was maintained wherever it was found in the world (Forbes et al. 1998).

The US-1 lineage, characterized primarily by a Ib mt-DNA haplotype, dominated worldwide population during the mid-20th century and was originally suspected to be responsible for the famine-era disease outbreaks (Goodwin et al. 1994). However, it is now clear that these were actually due to a lineage with a Ia mtDNA haplotype (Birch and Cooke 2013; May and Ristaino 2004). The famine-era MLG, FAM-1, was itself displaced by the US-1 (Saville et al. 2016), which was, in turn, replaced by new genotypes carried over in a shipment of potato from Mexico in 1976 (Birch and Cooke 2013). The precise timing of the displacement of FAM-1 by US-1 is not known but it is believed to have taken place before World War II (Saville et al. 2016). Thus, US-1 was probably dominant in Europe 
at the time of the introduction of P. infestans in eastern Africa in 1941, and is assumed to be the only lineage introduced into the region then.

Migration of $P$. infestans has had a big influence on shaping its population structure and dynamics worldwide. The pathogen is thought to have originated in central Mexico, owing to populations characteristics in this area such as high genetic diversity, presence of A1 and A2 mating types, and the presence of two close relatives (P. mirabilis and P. ipomoeae) in that region (Goss et al. 2014; Grünwald and Flier 2005). However, other reports point to a South American origin because the Andes are the center of origin of cultivated potato and variations of Andean lineages of $P$. infestans were found there (Gómez-Alpizar et al. 2007). For the latter hypothesis, $P$. infestans is assumed to have migrated to Mexico from South America (Niederhauser 1991). The pathogen reached Europe in 1845 (Bourke 1964) and, from there, it spread to other potatogrowing regions of the world, including Africa (Cox and Large 1960). The first introduction of $P$. infestans into Europe only brought the A1 mating type but, in a second migration event in 1976, the A2 mating type was introduced (Birch and Cooke 2013). The A2 mating type has also been reported in North Africa, and this could be attributed to the high volume of seed potato tubers and, consequently, new pathogen strains imported into Algeria, Egypt, Morocco, and Tunisia from European countries (van Loon 2007). In eastern Africa, only the A1 mating type has been detected thus far (Njoroge et al. 2016; Pule et al. 2013; Were et al. 2013), signifying the persistence of a clonal population.

Population shifts of either clonal or sexual populations have similar epidemiological consequences because they are the result of emergence of fitter pathogen genotypes (Day and Shattock 1997; Hohl 1998). Sexual populations of $P$. infestans give rise to longlived oospores in the soil (Mayton et al. 2000), as well as greater genotypic variation via sexual recombination (Shattock et al. 1986b). Clonal populations create intralineage variations via accumulation of mutations or mitotic recombination (Goodwin 1997; Grünwald 2012). Knowledge of $P$. infestans population structure within a region helps in understanding whether different strains have arisen and increased in frequency over time, hence providing a better insight into pathogen migrations. Disease management strategies can then be refined by knowledge of the phenotypic characteristics of the prevailing pathogen strains such as host range or fungicide sensitivity. Additionally, P. infestans populations can differ dramatically among countries and locations, and predictions concerning their phenotypic behavior need to be based on the correct population structure in a region.

In the eastern-Africa Region (EAR), US-1 had been the only $P$. infestans lineage reported, apart from appearances of Ia mtDNA haplotypes in Rwanda in the mid-1980s that were designated as RW-1 and RW-2 (Forbes et al. 1998; Goodwin et al. 1994). These authors reported that the two Rwandan genotypes (RW-1 and RW-2) were co-occurring with US-1 in that country. However, the RW-1 and RW-2 genotypes were not detected in a later study in 2007 that reported all $P$. infestans isolates from Rwanda to be US-1 (Pule et al. 2013). Pule et al. (2013) also reported that US-1 was still the only lineage in central and eastern Africa apart from Kenya, where US-1 and a new lineage were found. The new lineage, designated as KE-1, was reported in Kenya in 2007 (Pule et al. 2013) and in Uganda in 2011 (Njoroge et al. 2016). KE-1 was later found to be the only lineage on potato in Kenya (Njoroge et al. 2016), having earlier been found in only two fields in 2007 (Pule et al. 2013). Njoroge et al. (2016) also found that the KE-1 lineage was, in fact, the European 2_A1 lineage, which comprised about half of Great Britain's population in the mid-1990s (Day et al. 2004).

The suspicion that KE-1 and 2_A1 were the same lineage was raised by Were et al. (2013) but was not confirmed at the time. In contrast, Pule et al. (2013) supposed that the KE-1 lineage could be the RW genotypes reported in Rwanda in the mid-1980s. In neighboring Ethiopia, a study in 2002 revealed a population of only Ia mtDNA isolates (Schiessendoppler and Molnar 2002). More recently, a subsequent study revealed several lineages coexisting in the country, including a novel lineage with an unknown mtDNA haplotype (Shimelash et al. 2016). Subsequently, a comparison of the SSR fingerprints of the Ia populations in Ethiopia and Kenya indicated that they are identical (Njoroge et al. 2016). Although it has never been clarified whether Ethiopia is the source of the KE-1 population in Kenya, it is evident that the shared population is of European origin. Both countries import seed potato from Europe.

In Kenya, late blight on tomato was first recorded in 1944 and, by 1945, the disease was widespread on tomato in Tanzania (Wallace and Wallace 1945) and later found in Uganda in late 1954 (Baldwin 1956). From population studies conducted between the late 1990s and 2012, it appears that a single US-1 clonal lineage was found on tomato and potato in eastern Africa (Njoroge et al. 2016; VegaSanchez et al. 2000). The US-1 isolates from tomato and potato were shown to be host specific in detached-leaf tests and the two pathogen subpopulations also differed for one allele of $G p i$, an allozyme previously used to characterize populations of $P$. infestans. Furthermore, a recent pathogen effector gene study looking at the IpiO (Avrblbl) gene variants has revealed effector profile differences between the potato and tomato-adapted US-1, further confirming their difference (A. W. Njoroge, M. Ghislain, B. Andersson, E. Magembe, C. Mutai, R. Pelle, J. Yuen, and G. Forbes, unpublished data). It is possible that the difference in time of the first appearances of late blight on potato and tomato in Kenya might mean that the $P$. infestans strains have been host specific ever since their initial introduction, as indicated by early studies on the disease in the region (Cox and Large 1960). The selective displacement of US- 1 by KE- 1 only on potato in some countries could be due to adaptation to tomato in US-1 that has not (or not yet) occurred in KE-1.

Although current populations of US- 1 in the EAR exhibit features that could be considered beneficial to the pathogen, such as a high level of metalaxyl resistance (Mukalazi et al. 2001), the dominance of KE-1 lineage suggests that it has some attributes that result in a higher fitness compared with the previously established lineage. The date of introduction into Kenya of KE-1 as the European 2_A1 lineage is unknown, although the route of introduction is believed to be seed potato importation from Europe. In this study, we tested the hypothesis that the European strain 2_A1 has recently dominated the P. infestans population in the EAR. We present an analysis of the population structure of $P$. infestans sampled on potato and tomato between December 2013 and June 2016 in five eastern Africa countries (namely, Kenya, Uganda, Tanzania, Burundi, and Rwanda) using SSR markers.

\section{MATERIALS AND METHODS}

Sampling of late-blight-infected plant material. Samples of diseased potato leaflets were collected from growers' fields (Supplementary Fig. S1) in 2013 (Uganda), 2014 (Uganda and Kenya), 2015 (Uganda, Kenya, Rwanda, Burundi, and Tanzania), and 2016 (Uganda, Kenya, Burundi, and Tanzania). Additionally, samples were taken from farmers' fields containing different potato cultivars being evaluated for susceptibility to late blight in southwestern Uganda (2013-14); from field trials on the experimental station of Uganda's National Agricultural Research Organization at the Kachwekano zonal agricultural research and development institute (2015), where Dutch potato cultivars were under evaluation; and from a confined field trial (2015) with transgenic potato lines. The greatest number of samples came from Uganda, (447 potato, 110 tomato), followed by Kenya (271 potato, 43 tomato), Rwanda (180 potato, 8 tomato), Burundi ( 82 potato), and Tanzania (76 potato, 4 tomato). Single lesions from diseased leaflets were individually pressed onto Whatman FTA cards (Whatman FTA Classic Card, catalog number WB120205: GE Healthcare UK Ltd.) in the field; the cards were subsequently air dried before storage until they were moved to the laboratory for SSR analysis. In total, 22 reference DNA samples (FTA discs) of the 
2_A1 lineage, provided by Dr. Alison Lees (James Hutton Institute, Dundee, United Kingdom), were included in the analysis. The samples from Dr. Lees had been previously described by Were et al. (2013), who identified the lineage as 2_A1.

Eluting DNA from the FTA cards. To elute the DNA from the FTA cards, a method by Njoroge et al. (2016) was used but modified to include a $\mathrm{pH}$-treatment step. A single 6-mm disc was punched out from the applied dry sample spot and transferred into a $1.5-\mathrm{ml}$ microfuge tube. The disc was washed twice with $400 \mu \mathrm{l}$ of FTA purification reagent (Whatman Inc., USA) followed by two rinses with $400 \mu \mathrm{l}$ of modified Tris-EDTA buffer $(10 \mathrm{mM}$ Tris and $0.1 \mathrm{mM}$ EDTA). The $\mathrm{pH}$ treatment process involved incubating the washed FTA disc in $70 \mu \mathrm{l}$ of alkaline buffer (solution 1: $0.1 \mathrm{~N} \mathrm{NaOH}$ and $0.3 \mathrm{mM}$ EDTA, $\mathrm{pH} 13.0$ ) for $5 \mathrm{~min}$ at room temperature. Thereafter, $130 \mu \mathrm{l}$ of neutralization buffer (solution 2: $0.1 \mathrm{M}$ Tris$\mathrm{HCl}, \mathrm{pH}$ 7.0) was added, vortexed five times to mix, then incubated for $10 \mathrm{~min}$ at room temperature. The FTA discs were left in the final solution and kept at $-20^{\circ} \mathrm{C}$ until use.

Confirmation of $P$. infestans DNA presence in FTA elutes using internal transcribed spacer region primers. The eluted solution from the FTA cards was tested for the presence of $P$. infestans DNA using a primer-pair, internal transcribed spacer (ITS)5 (GGAAGTAAAAGTCGTAACAAGG) as the forward primer and a species-specific primer Pinf2 (CTCGCTACAATAG CAGCGTC) as the reverse primer in a polymerase chain reaction (PCR). The PCR was performed in a $10-\mu l$ volume containing $2 \mu \mathrm{l}$ of the FTA eluate, $0.25 \mu \mathrm{M}$ each primer, and $5 \mu \mathrm{l}$ of AccuPower Taq PCR $2 \times$ master mix (Bioneer). Amplifications were performed in Eppendorf AG 22331 Hamburg thermocycler under the following conditions: initial denaturation at $94^{\circ} \mathrm{C}$ for $2 \mathrm{~min}$; followed by 35 cycles of $15 \mathrm{~s}$ at $94^{\circ} \mathrm{C}, 15 \mathrm{~s}$ at $55^{\circ} \mathrm{C}$, and $15 \mathrm{~s}$ at $72^{\circ} \mathrm{C}$; and a final extension of $5 \mathrm{~min}$ at $72^{\circ} \mathrm{C}$. Visualization of the PCR amplicons was done on agarose gel electrophoresis.
SSR multiplex reactions and uniplex PCR. Determination of the $P$. infestans SSR alleles was done in two laboratories. The samples collected in Uganda and Kenya from 2013 to mid-2014 were analyzed in single primer reactions using nine SSR markers chosen from previously published markers (Table 1) at the Swedish University of Agricultural Sciences (SLU-Uppsala) in 2014. The other set of samples collected between December 2014 and June 2016 was analyzed at the Biosciences central and eastern AfricaInternational Livestock Research Institute (BecA-ILRI) hub in Nairobi, Kenya, in 2017, using a modified version of the 12-plex single SSR protocol previously described by Li et al. (2013). Additionally, for the 2017 analysis at the BecA-ILRI hub, a uniplex reaction was set up with an additional 13th marker, Pi56 (Lees et al. 2006). The primer concentrations in the multiplex reaction were adjusted for our laboratory conditions to between 0.16 and $0.3 \mu \mathrm{M}$ (Table 1). The Qiagen Type-It Microsatellite PCR kit (Qiagen Corporation) was used for PCR and sample volumes were modified to run a $12.5-\mu \mathrm{l}$ reaction using $6.25 \mu \mathrm{l}$ of $2 \times$ Type-It Master Mix, $1.3 \mu \mathrm{l}$ of a $10 \times$ multiplex primer mix, $1.95 \mu \mathrm{l}$ of water, and $3 \mu \mathrm{l}$ of FTA eluate. For the single primer reactions, AccuPower Taq PCR $2 \times$ master mix (Bioneer) was used and all primers were used at a final concentration of $0.25 \mu \mathrm{M}$. The amplification conditions for the multiplex PCR were as follows: $95^{\circ} \mathrm{C}$ for $5 \mathrm{~min}$; followed by 33 cycles of $95^{\circ} \mathrm{C}$ for $30 \mathrm{~s}, 58^{\circ} \mathrm{C}$ for $90 \mathrm{~s}$, and $72^{\circ} \mathrm{C}$ for $30 \mathrm{~s}$; and a final extension at $60^{\circ} \mathrm{C}$ for $30 \mathrm{~min}$. For the single primer reactions, the cycling conditions were as follows: initial denaturation at $94^{\circ} \mathrm{C}$ for $3 \mathrm{~min}$; followed by 33 cycles of $30 \mathrm{~s}$ at $94^{\circ} \mathrm{C}, 30 \mathrm{~s}$ at $62^{\circ} \mathrm{C}(\mathrm{Pi0} 4$ and $\mathrm{PiG} 11), 60^{\circ} \mathrm{C}(\mathrm{Pi} 16), 58^{\circ} \mathrm{C}(\mathrm{Pi} 56, \mathrm{Pi} 70$, Pi89, and $\mathrm{Pi} 4 \mathrm{~B})$, or $50^{\circ} \mathrm{C}$ (D13), and $45 \mathrm{~s}$ at $72^{\circ} \mathrm{C}$; and completed with a final extension step of $25 \mathrm{~min}$ at $72^{\circ} \mathrm{C}$.

SSR fragment analysis and scoring. To confirm successful amplification and band intensity, $5 \mu \mathrm{l}$ of PCR product was mixed with $1 \mu \mathrm{l}$ of $6 \times$ gel loading dye and separated on $2.5 \%(\mathrm{wt} / \mathrm{vol})$

TABLE 1. Phytophthora infestans simple sequence repeat (SSR) primers used in this study for the multiplex and single primer reactions

\begin{tabular}{|c|c|c|c|}
\hline Primer & Reaction type & Primer sequence + dyes $^{\mathrm{a}}$ & Final Con $(\mu \mathrm{M})^{\mathrm{b}}$ \\
\hline \multirow[t]{2}{*}{ PiG11 ${ }^{\mathrm{c}}$} & Multiplex, uniplex & Fwd_NED-TGCTATTTATCAAGCGTGGG & 0.15 \\
\hline & $\ldots$ & Rev_GTTTCAATCTGCAGCCGTAAGA & 0.15 \\
\hline \multirow[t]{2}{*}{ Pi02/PinfSSR $3^{\text {d,e }}$} & Multiplex & Fwd_NED-ACTTGCAGAACTACCGCCC & 0.15 \\
\hline & $\ldots$ & Rev_GTTTGACCACTTTCCTCGGTTC & 0.15 \\
\hline \multirow[t]{2}{*}{ PinfSSR $11^{\mathrm{e}}$} & Multiplex & Fwd_NED-TTAAGCCACGACATGAGCTG & 0.15 \\
\hline & $\ldots$ & Rev_GTTTAGACAATTGTTTTGTGGTCGC & 0.15 \\
\hline \multirow[t]{2}{*}{$\mathrm{D} 13^{\mathrm{d}}$} & Multiplex, uniplex & Fwd_FAM-TGCCCCCTGCTCACTC & 0.16 \\
\hline & $\ldots$ & Rev_GCTCGAATTCATTTTACAGACTTG & 0.16 \\
\hline \multirow[t]{2}{*}{ PinfSSR8 $8^{e}$} & Multiplex & Fwd_FAM-AATCTGATCGCAACTGAGGG & 0.3 \\
\hline & $\ldots$ & Rev_GTTTACAAGATACACACGTCGCTCC & 0.3 \\
\hline \multirow[t]{2}{*}{ PinfSSR4 $^{\mathrm{e}}$} & Multiplex & Fwd_FAM-TCTTGTTCGAGTATGCGACG & 0.15 \\
\hline & $\ldots$ & Rev_GTTTCACTTCGGGAGAAAGGCTTC & 0.15 \\
\hline \multirow[t]{2}{*}{$\mathrm{PiO}^{\mathrm{d}}$} & Multiplex, uniplex & Fwd_VIC-AGCGGCTTACCGATGG & 0.15 \\
\hline & $\ldots$ & Rev_GTTTCAGCGGCTGTTTCGAC & 0.15 \\
\hline \multirow[t]{2}{*}{$\mathrm{Pi}^{\mathrm{d}} \mathrm{d}^{\mathrm{L}}$} & Multiplex, uniplex & Fwd_VIC-ATGAAAATACGTCAATGCTCG & 0.15 \\
\hline & $\ldots$ & Rev_CGTTGGATATTTCTATTTCTTCG & 0.15 \\
\hline \multirow[t]{2}{*}{ PinfSSR6 $^{\mathrm{e}}$} & Multiplex & Fwd_VIC-GTTTTGGTGGGGCTGAAGTTTT & 0.15 \\
\hline & $\ldots$ & Rev_TCGCCACAAGATTTATTCCG & 0.15 \\
\hline \multirow[t]{2}{*}{$\mathrm{Pi}^{\mathrm{d}}$} & Multiplex, uniplex & Fwd_VIC-ATGACGAAGATGAAAGTGAGG & 0.15 \\
\hline & $\ldots$ & Rev_CGTATTTTCCTGTTTATCTAACACC & 0.15 \\
\hline \multirow[t]{2}{*}{ PinfSSR2 $^{e}$} & Multiplex & Fwd_PET-CGACTTCTACATCAACCGGC & 0.15 \\
\hline & $\ldots$ & Rev_GTTTGCTTGGACTGCGTCTTTAGC & 0.15 \\
\hline \multirow{2}{*}{$\mathrm{Pi} 4 \mathrm{~B}^{\mathrm{c}}$} & Multiplex, uniplex & Fwd_PET-AAAATAAAGCCTTTGGTTCA & 0.3 \\
\hline & $\ldots$ & Rev_GCAAGCGAGGTTTGTAGATT & 0.3 \\
\hline \multirow[t]{2}{*}{$\operatorname{Pi} 56^{\mathrm{d}}$} & Uniplex & Fwd_FAM-ACAACTATCTATCGGCGTGC & 0.25 \\
\hline & $\ldots$ & Rev_AGTAGGCTTCACGACCAGC & 0.25 \\
\hline \multirow[t]{2}{*}{$\operatorname{Pi}^{\mathrm{d}} 6^{\mathrm{d}}$} & Uniplex & Fwd_FAM-CACAGCACGCGGAATC & 0.25 \\
\hline & $\ldots$ & Rev_ACGCCGAGTGTCCTGA & 0.25 \\
\hline \multirow[t]{2}{*}{ Pi89d } & Uniplex & Fwd_FAM-GAGAACGCACAATGTAAGGC & 0.25 \\
\hline & $\ldots$ & Rev_ACATAAATACACGCTGAACGG & 0.25 \\
\hline
\end{tabular}

a Primer sequences and the different fluorescent dyes (NED, FAM, VIC, or PET) added to the different forward primers.

b Primer concentrations used for our laboratory conditions.

c Primers previously reported by Knapova and Gisi (2002).

d Primers previously reported by Lees et al. (2006).

e Primers previously reported by Li et al. (2010). 
agarose gel. The band intensities were used to estimate the amount of PCR amplicons present in each sample. Dilutions were made using 1 to $1.5 \mu \mathrm{l}$ of the PCR products by mixing them with $9 \mu \mathrm{l}$ of distilled deionized water. To prepare samples for fragment analysis, $1 \mu \mathrm{l}$ of the diluted PCR product was mixed with a 9- $\mu \mathrm{l}$ mix of $\mathrm{HiDi}$ (400 $\mu \mathrm{l}$; Hi-Di Formamide part number 4311320; Applied Biosystems) and GeneScan-500LIZ standard (6 $\mu \mathrm{l}$; part number 4322682). The samples were submitted to the Segoli Laboratory (BecA-ILRI hub, Nairobi, Kenya) while those in Sweden were submitted to the Uppsala Genome Center at Rudbeck Laboratory (Uppsala University, Sweden). Fragment analysis of the samples was done on an automated ABI 3730 capillary sequencer according to the manufacturer's instruction at both locations. In Sweden, allele sizes were scored using the software GENEMARKER (Soft Genetics) while, at the BecA-ILRI hub, allele sizes were determined using GeneMapper v3.7 software (Applied Biosystems).

mtDNA haplotype analysis. mtDNA haplotypes were determined for 62 samples selected from the 223 samples analyzed in Sweden. The 62 samples represented all of the SSR MLGs generated from subpopulations defined according to host origin and clonal lineage. Haplotyping was done using the RFLP method of Griffith and Shaw (1998). Two mtDNA haplotypes were tested using the primer pair P2F (TTCCCTTTGTCCTCTACCGAT) and P2R (TTACGGCGGTTTAG CACATACA) and primer pair P4F (TGGTCATCCAGAGGTT TATGTT) and P4R (CCGATACCGATACCAGCACCAA), specific for the $\mathrm{P} 2$ and $\mathrm{P} 4 \mathrm{mtDNA}$ regions, respectively. The $\mathrm{PCR}$ consisted of $1 \times$ Green buffer, $0.1 \mathrm{mM}$ dNTP each, $1.5 \mathrm{mM} \mathrm{MgCl} 2,0.32 \mu \mathrm{M}$ each forward and reverse primer, and 1.5 U of Dream Taq (Fermentas) in a $25-\mu \mathrm{l}$ final volume. The cycling conditions were as follows: $94^{\circ} \mathrm{C}$ for $3 \mathrm{~min}$; followed by 30 cycles of $94^{\circ} \mathrm{C}$ for $30 \mathrm{~s}, 62^{\circ} \mathrm{C}$ for $30 \mathrm{~s}$, and $72^{\circ} \mathrm{C}$ for $60 \mathrm{~s}$; and a final extension at $72^{\circ} \mathrm{C}$ for $5 \mathrm{~min}$. Amplified products $(10 \mu \mathrm{l})$ of the P2 and P4 regions were digested with MspI and EcoRI restriction enzymes, respectively. The resulting products were visualized by agarose gel electrophoresis to distinguish the resulting mtDNA haplotypes.

Datasets. Three datasets were used for analyses in this study as follows:

i. The 2014 dataset comprised 223 samples collected on potato and tomato between 2013 and mid-2014 from Kenya and Uganda. This dataset was generated using nine SSR markers in single PCR at SLU-Uppsala. The dataset could not be combined with the 2017 dataset (see below) due to dissimilarity in the type of SSR markers and laboratory protocols used; hence, it was analyzed separately.

ii. The 2017 dataset with 1,013 samples was collected between December 2014 to June 2016 in Kenya, Uganda, Tanzania, Rwanda, and Burundi on potato and tomato. This dataset was created using 13 SSR markers in a single 12-plex and uniplex (Pi56) reaction at the BecA-ILRI hub in Kenya. The dataset

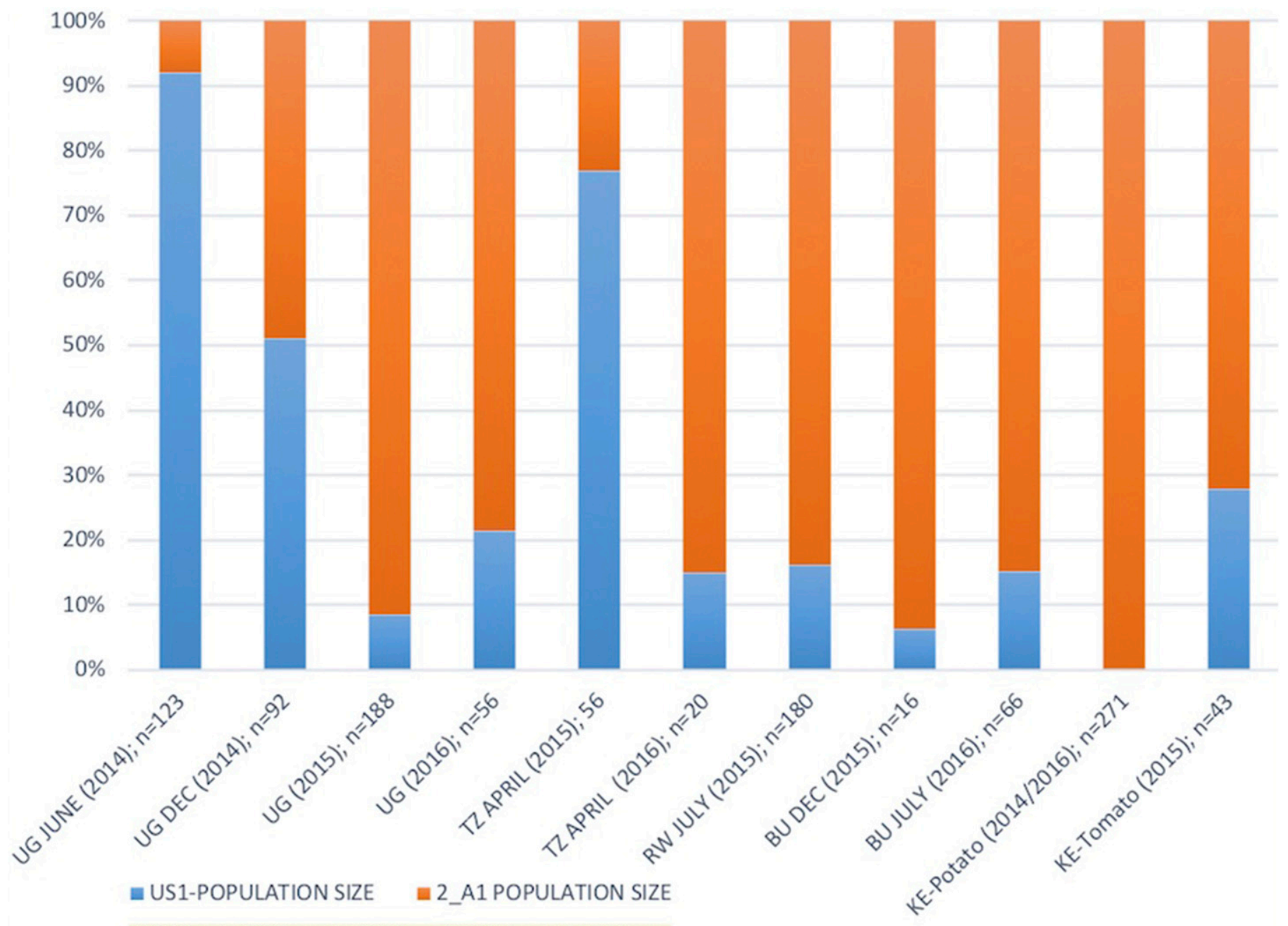

UG-Uganda; TZ-Tanzania; RW-Rwanda; BU-Burundi; KE-Kenya

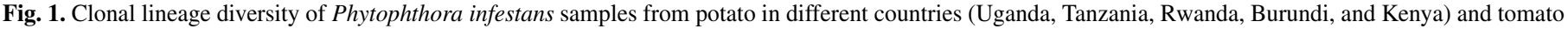

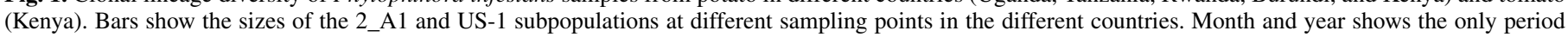

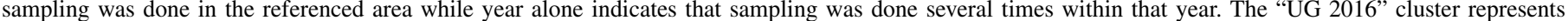
samples from southwestern Uganda, the only region sampled that year in Uganda. The number of samples at each sampling point is represented by " $n$ ". 
was analyzed both separately and combined with the reference samples (see below), depending on the different population parameters that were analyzed.

iii. The 2017 full dataset comprised all the samples in the 2017 dataset and an additional 22 reference samples. The reference samples had been previously collected in Kenya in 2009. They were genotyped using a similar genotyping protocol used for the 2017 dataset and, henceforth, assigned the name KenyaRef, for purposes of comparisons in the subsequent analyses.

Assignment of clonal lineages. The 2014 dataset and 2017 dataset were used for comparison against the reference samples to establish whether samples belonged to the US-1 or KE-1 lineage.

MLG analyses. Samples with the same combination of alleles (i.e., similar MLGs) were considered to be clones. The number of MLGs in each population and the expected number of MLGs after rarefaction (eMLG) (Hurlbert 1971) were obtained using the R package Poppr (Kamvar et al. 2014).

Genetic diversity indices. Basic indices of genetic variation for each population were calculated for populations defined by lineages (KE-1 or US-1) and subpopulation host (tomato or potato) for the 2014 dataset and 2017 full dataset. Clonal diversity within the populations was described using the Simpson diversity (Simpson 1949) and the Shannon-Wiener index (Shannon 2001); genetic richness $(\mathrm{R})$, which, in this case, is equivalent to the number of eMLG at the largest shared sample size; and the Hendrick's standardized Index $\left(G_{S T}^{\prime}\right)$, which determines within-population genetic diversity for multiallelic markers (Hedrick 1999; Hedrick 2005). An index of $G^{\prime}{ }_{S T}=0$ indicates that populations are fixed for a single allele while $G_{S T}^{\prime}=1$ indicates that populations have no overlapping sets of alleles (Meirmans and Hedrick 2011).

Population structure and differentiation. Estimation of genetic distance between individuals was based on the method of Bruvo et al. (2004), which uses a stepwise mutation model to calculate genetic distance of individuals in the population using the $\mathrm{R}$ package POLYSAT (Clark and Jasieniuk 2011). Significance was assessed using 1,000 bootstrap replicates. Genetic groupings of individuals within a clonal lineage were viewed using a discriminant

TABLE 2. Summary of multilocus genotype diversity found in the Phytophthora infestans subpopulations found in different countries and on different hosts for the 2017 full dataset

\begin{tabular}{|c|c|c|c|c|c|c|c|}
\hline \multirow[b]{2}{*}{ Country } & \multirow[b]{2}{*}{ Lineage $^{\mathrm{b}}$} & \multicolumn{2}{|c|}{ Potato } & \multicolumn{2}{|c|}{ Tomato } & \multicolumn{2}{|c|}{ All samples ${ }^{\mathrm{a}}$} \\
\hline & & $N^{\mathrm{c}}$ & $\mathrm{eMLG}^{\mathrm{d}}$ & $N^{\mathrm{c}}$ & $\mathrm{eMLG}^{\mathrm{d}}$ & $N^{\mathrm{e}}$ & All eMLG ${ }^{f}$ \\
\hline \multirow[t]{3}{*}{ Burundi } & 2_A1 & 68 & 8.11 & $\ldots$ & $\ldots$ & $\ldots$ & $\ldots$ \\
\hline & US-1 & 11 & 10 & $\ldots$ & $\ldots$ & & $\ldots$ \\
\hline & All & & & & & 79 & 49 \\
\hline \multirow[t]{4}{*}{ Kenya } & 2_A1 & 232 & 7.19 & 31 & 9.61 & $\ldots$ & $\ldots$ \\
\hline & US-1 & & & 12 & 9.32 & $\ldots$ & $\ldots$ \\
\hline & 2_A1REF & 22 & 7.68 & $\ldots$ & $\ldots$ & $\ldots$ & $\ldots$ \\
\hline & All & & & $\ldots$ & $\ldots$ & 275 & 44.5 \\
\hline \multirow[t]{3}{*}{ Rwanda } & 2_A1 & 151 & 7.35 & $\ldots$ & $\ldots$ & $\ldots$ & $\ldots$ \\
\hline & US-1 & 29 & 9.12 & 8 & 5 & $\ldots$ & $\ldots$ \\
\hline & All & $\ldots$ & $\ldots$ & $\ldots$ & $\ldots$ & 188 & 41.1 \\
\hline \multirow[t]{3}{*}{ Uganda } & 2_A1 & 260 & 6.57 & $\ldots$ & $\ldots$ & $\ldots$ & $\ldots$ \\
\hline & US-1 & 75 & 9.73 & 56 & 9.77 & $\ldots$ & $\ldots$ \\
\hline & All & $\ldots$ & $\ldots$ & $\ldots$ & $\ldots$ & 391 & 46.9 \\
\hline \multirow[t]{3}{*}{ Tanzania } & 2_A1 & 30 & 8.27 & $\ldots$ & $\ldots$ & $\ldots$ & $\ldots$ \\
\hline & $\overline{\mathrm{US}}-1$ & 46 & 9.79 & 4 & 3 & . & $\ldots$ \\
\hline & All & $\ldots$ & $\ldots$ & $\ldots$ & $\ldots$ & 80 & 64.3 \\
\hline
\end{tabular}

a Number of all Phytophthora infestans samples in the respective countries.

b Denotes the $P$. infestans clonal lineage; 2_A1REF represents the reference samples.

c Number of samples from each clonal lineage in each country on either potato or tomato.

d Expected number of multilocus genotypes (eMLGs) for each clonal lineage after rarefaction (or genetic richness at the largest shared sample size) on either potato or tomato.

e Total number of samples from each country.

f eMLGs for all samples after rarefaction for each country. analysis of principal components (DAPC) (Jombart et al. 2010) using the R package ADEGENET (Jombart and Ahmed 2011).

Minimum-spanning networks to test evolutionary relationships among individuals for each subpopulation (KE-1 or US-1), were constructed and visualized for different regions and hosts, using the R package Poppr (Kamvar et al. 2014).

The proportion of genetic variability between and within clonal genotypes was determined by an analysis of molecular variance (AMOVA) using (Weir and Cockerham 1984) an unbiased estimator of fixation index in the ade4 $\mathrm{R}$ package (Dray and Dufour 2007).

\section{RESULTS}

The findings from this study confirm that the $P$. infestans population infecting potato in the EAR, represented here by five countries, is dominated by $\mathrm{KE}-1$ lineage, a clonal lineage of European origin. KE-1 and the European 2_A1 had similar SSR fingerprints for the SSR loci that identify this lineage, as well as being of the Ia mtDNA haplotype, and, thus, are assumed to be the same. The KE-1 lineage will hereafter be referred to as 2_A1. The US-1 lineage was found to have diminished significantly but was still present on potato in Uganda, Rwanda, Burundi, and Tanzania. Additionally, a tomato-adapted US-1 subpopulation was also still present in all of the countries.

A rapid displacement of the old US-1 lineage by 2_A1 was observable in all countries, particularly on potato. The 2_A1 was the only lineage on potato in Kenya. However, in Uganda, Rwanda, Burundi, and Tanzania, both 2_A1 and US-1 were found on this host. In some instances, the two lineages were found coexisting in the same field. A notable example was one field in Uganda's Kabale district where, out of eight potato plants sampled during the dry season in February 2016, five were 2_A1 and three were US-1.

The population change over time was particularly evident in Uganda, where samples collected every cropping season showed a rapid increase of the 2_A1 lineage between December 2013 (23\%) and December 2015 (91.5\%). In southwestern Uganda, 2_A1 was first observed in December 2014 but made up three-quarters of the samples collected in April 2016. A similar, rapid increase in 2_A1 frequency was observed in Tanzania, where it increased to $85 \%$ frequency within a year. 2_A1 also appeared and spread in 2015-16 in Rwanda and Burundi, where it had not been observed before. Finally, 2_A1 spread to tomato in Kenya, a host from which it was previously absent (Fig. 1).

The $P$. infestans population across the countries had varying diversity, as demonstrated by the eMLGs. Tanzania had the most diverse $P$. infestans population while Rwanda displayed the least diversity (Table 2). Burundi, Uganda, and Kenya had almost similar diversity, ranking in that order in total eMLGs (Table 2). Notable, though, was the presence of unique alleles on the US-1 subpopulation in Tanzania in one of the SSR markers that identifies the US-1 lineage. The $P$. infestans samples from Tanzania had private alleles on the Pi02 locus, 264/270 and 266/272, in place of 266/266, which generally identifies the US-1 lineage. Dissimilarity of the Tanzanian US-1 from the US-1 populations in the other countries was also evident in the cluster analyses, where the two Tanzanian subpopulations on potato and tomato formed a distinct cluster in the DAPC (Fig. 2). Multiple occurrences of similar MLGs was noted across the countries, with Kenya and Burundi sharing the highest number of such genotypes. Consequently, these $P$. infestans populations in the two countries were more aggregated than the subpopulations in the other countries in the DAPC (Fig. 3).

MLG variability was found for both 2_A1 and the diminishing resident US-1 subpopulations on potato and tomato. Diverse MLGs of the 2_A1 lineage were found even at the field level and no field had a $P$. infestans population consisting of a single MLG. Although both lineages had high diversity, there was a higher MLG diversity in US-1 (85\%) than in 2_A1 (36\%). Greater MLG diversity was also evident on tomato $(84.7 \%)$ than on potato (43.8\%) US-1 subpopulations. Across the countries, Burundi's 
US-1 subpopulation on potato had a higher genetic richness at the largest shared sample size (eMLG) than did the US-1 potato subpopulations in the other countries (Table 2). Even though the 2_A1 subpopulation on tomato was only found in Kenya, it was equally diverse, with nearly all of the samples representing a distinct MLG. Within the subpopulations of each lineage on the two hosts, the US-1 lineage and, particularly, the subpopulation on potato exhibited higher genetic diversity, as indicated by three diversity indices (Nei's index, Simpsons's index, and Shannon's index) (Table 3). The intralineage variability observed within the clonal lineages was attributable to some but not all the 13 SSR markers used in this study. The SSR markers D13, PiG11, and PinfSSR4 had the highest polymorphism (number of alleles), hence resulting in a higher number of MLGs within the two clonal lineages (Table 4). High genetic similarity existed between the 2_A1 subpopulations on potato and tomato, as shown by shared nodes on the minimum spanning network (Fig. 4) and overlapping of clones on the DAPC (Fig. 5). Some genetic dissimilarity as shown by the AMOVA was found, however, in the 2_A1 lineage across the countries (Table 5), despite the lineage forming a cluster of its own in the DAPC, with many overlapping samples from different countries.

Host specificity of the US-1 lineage on tomato was evident in all countries. In every country other than Kenya, the tomato-adapted US-1 was the only lineage found on tomato. In Kenya, however, both 2_A1 and the tomato-adapted US-1 were found to co-occur. The lack of shared SSR MLGs between potato and tomato within the US-1 subpopulations was noteworthy. The genetic dissimilarity between the two US-1 subpopulations, although somewhat minimal (13\%) as revealed by AMOVA (Table 5), was evident in the cluster analyses. The tomato-adapted US-1 clustered away from the US-1 on potato (Fig. 5). However, within the 2_A1 lineage, some of the genotypes appearing on tomato were also found on potato in Kenya, Burundi, and Uganda.

\section{DISCUSSION}

The evidence presented here supports the hypothesis of the occurrence and dominance of the European 2_A1 lineage in EAR. This study also demonstrated a pathogen population with relatively

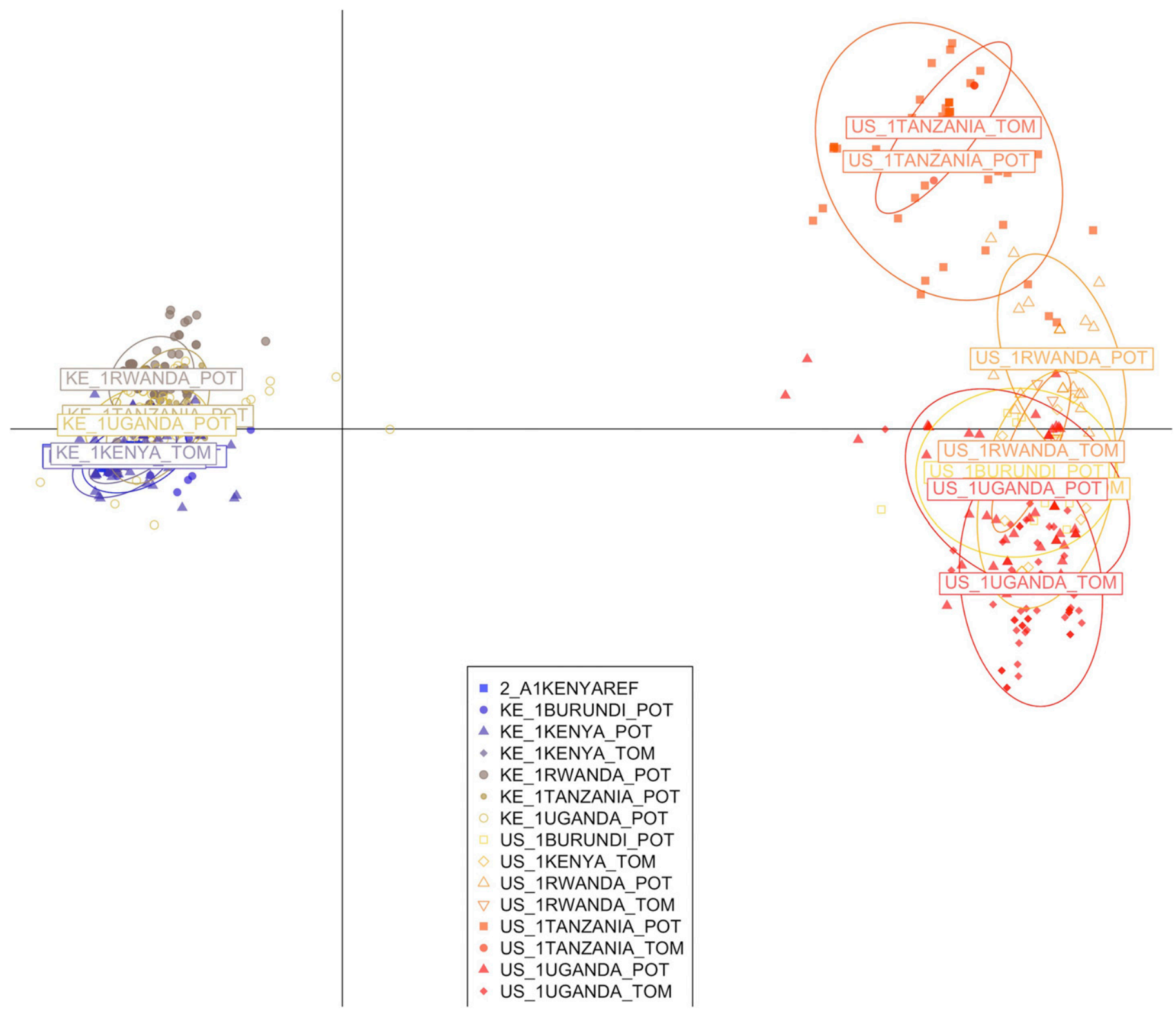

Fig. 2. Discriminant analysis of principal components (DAPC) of Phytophthora infestans samples in the 2017 full dataset showing lone clustering of the Tanzanian US-1 subpopulations. Twelve principal component analyses determined via cross validation were used to show the clustering. The 2017 full dataset includes the 2_A1 lineage reference samples, indicated by population 2_A1KenyaRef. Groups are represented by shade or symbol as well as by inertia ellipses. Each point represents a single clonal lineage grouped by population "clonal_lineage_country_host”. Pathogen clonal lineages represented are US_1(US-1) and KE_1 (KE-1). Countries represented are Burundi, Kenya, Rwanda, Tanzania, and Uganda. Hosts are potato (POT) and tomato (TOM). 
high genotype variation. Although this occurs and can be expected in parts of northern Europe, where sexual populations of $P$. infestans are dominant (Brurberg et al. 2011; Sjöholm et al. 2013), results from previous studies of subclonal variation in clonal pathogen populations have not been consistent. For example, Delgado et al. (2013) found high subclonal variation within the EC-1 lineage in Ecuador, whereas Blandón-Díaz et al. (2012) found very little diversity in the lineage in Nicaragua. Li et al. (2013) showed higher variation for D13 (seven allele combinations) and G11 (two allele combinations) with the clone identified as 13_A2.

It is not clear why there was higher variation in the Tanzanian US-1 subpopulation. The results here suggest that this subpopulation could be a variant of the US-1 population. This variation may be due to different potato cultivars grown there, specific microclimate, or even a separate introduction of US-1, although the latter would be inconsistent with the chronology of pathogen spread reported by (Natrass 1944).

Factors that may have contributed to subclonal diversity in the present study include a relatively large sample size and sampling of the population over time, on two hosts, and across a relatively large distance. The latter factor, however, is inconsistent with the fact that populations from the two most distant countries (Burundi and Kenya) were most similar. Delgado et al. (2013) discussed other factors that may lead to high subclonal diversity and reviewed the literature on this topic. However, it is evident from the current study that variation within lineages has arisen predominantly from polymorphisms at the three most variable SSR loci. The other loci that discriminate between the $P$. infestans lineages, mainly 2_A1 and US-1 in the eastern-Africa population, remain largely monomorphic within each lineage, other than the appearance of a few triploids.

Higher diversity in US-1 than in 2_A1 is probably attributable to the longer presence of US-1 in the region, as it is assumed to be the only $P$. infestans strain existing since the introduction of the disease in EAR in 1940s. The 2_A1 was identified in 1981 in Europe (Day et al. 2004) but was probably introduced into EAR relatively recently, presumably only as one or a few genotypes.

The apparent higher fitness of 2_A1 over US-1 may be due to several factors, but one could be the extended presence of US-1 in

\begin{tabular}{ll}
\hline & 2_A1KENYAREF \\
- & BURUNDI \\
KENYA \\
- RWANDA \\
- TANZANIA \\
- UGANDA \\
\hline
\end{tabular}

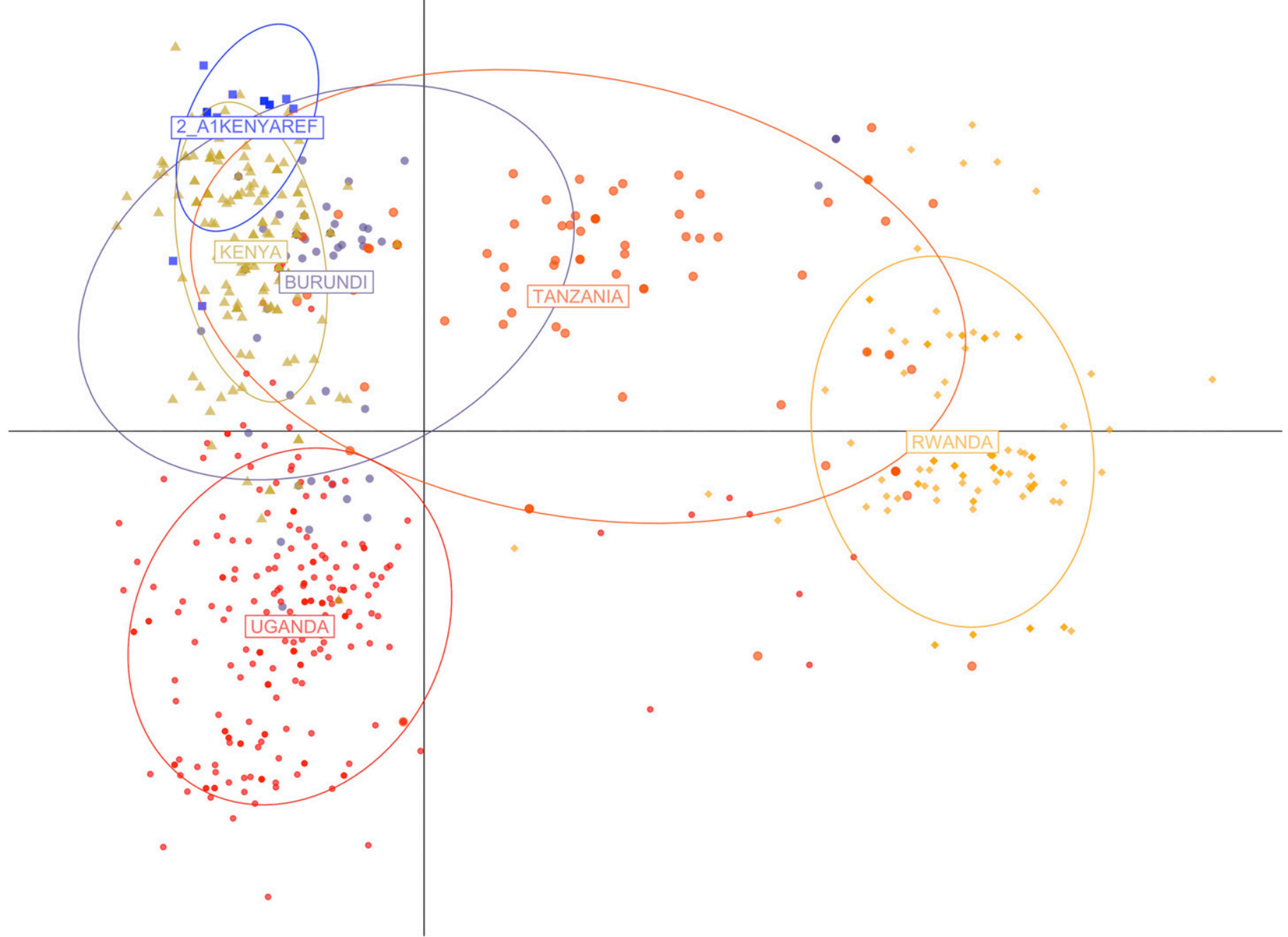

Fig. 3. Discriminant analysis of principal components (DAPC) of Phytophthora infestans samples in the 2017 full dataset showing more similarity in the Kenya and Burundi populations. Nine principal component analyses determined via cross validation were used to show the clustering of the individual samples from the five countries on both potato and tomato. Samples from the two hosts are not discriminated in the DAPC. The 2017 full dataset includes the 2_A1 lineage reference samples indicated by population 2_A1 KenyaRef. Groups are represented by shade or symbol as well as by inertia ellipses. Each point represents a single sample grouped by country. 
the region. One long-term evolutionary consequence of clonality is that deleterious mutations can accumulate and the resulting decline in fitness is the so-called Muller's ratchet effect in action (Goodwin 1997). This theory has been used to explain why lineages emerging from the sexually reproducing metapopulation described by Yoshida et al. (2013) displaced HERB-1, the lineage responsible for the Irish potato famine. In our case, the US-1 lineage was found to be less fit than 2_A1 for aggressiveness components (Njoroge et al. 2019) and this could explain, at least in part, why 2_A1 has dominated.

The westward migration of 2_A1 from eastern Uganda is likely to be the source of this lineage in Rwanda. Given the pattern of US-1 displacement, it is highly probable that 2_A1 is currently the only lineage on potato in Uganda. From the high number of 2_A1 samples obtained in Rwanda, Burundi, and Tanzania, none of which had initially reported 2_A1, one can speculate on a sequential appearance of this lineage in the aforementioned countries. However, all these countries share land borders and it is also possible that multiple migration events occurred across borders. Human movement across countries is quite common in the region and movement of plant material across borders is heightened when markets for farm produce open in the neighboring countries. For example, trucks heading to Kigali markets in Rwanda with potato tubers freshly harvested in Kabale, Uganda are common sights along the Kabale-Kigali road. Moreover, during conflicts, people move with farm produce across country borders, providing another potential mechanism for human-mediated $P$. infestans movement.

Notable from this study is the appearance of 2_A1 on tomato in Kenya, which could imply different scenarios. First, it may indicate that this lineage has adapted to both hosts although, with this scenario, there is no way of knowing from our data whether tomato is infected by a tomato-adapted subpopulation or by a dually adapted (potato and tomato) subpopulation. Answering that question would require cross inoculations on both hosts. A second scenario is that the 2_A1 isolates from tomato represent isolates that are not particularly adapted to tomato but were found on tomato because no tomato-adapted isolates were present. In a previous study, isolation of a potato-adapted genotype from tomato in Ecuador was explained by the absence of tomato-adapted genotypes at that location (Oyarzun et al. 1998). A relatively large number of MLGs was found among 2_A1 samples coming from

TABLE 3. Summary of diversity indices conducted on clonal genotypes of Phytophthora infestans (2_A1 and US-1) coming from both potato and tomato in the eastern-Africa region

\begin{tabular}{|c|c|c|c|c|c|c|c|}
\hline \multirow[b]{2}{*}{$\begin{array}{l}\text { Diversity } \\
\text { indices }\end{array}$} & \multicolumn{3}{|c|}{2014 dataset } & \multicolumn{4}{|c|}{2017 dataset } \\
\hline & $\begin{array}{l}\text { US-1 } \\
\text { Tom }^{\mathrm{a}}\end{array}$ & $\begin{array}{l}\text { US-1 } \\
\text { Pot }^{\mathrm{b}}\end{array}$ & $\begin{array}{c}\text { 2_A1 } \\
\text { Pot }^{c}\end{array}$ & $\begin{array}{l}\text { US-1 } \\
\text { Tom }^{\mathrm{a}}\end{array}$ & $\begin{array}{l}\text { US-1 } \\
\text { Pot }^{\mathrm{b}}\end{array}$ & $\begin{array}{c}\text { 2_A1 } \\
\operatorname{Pot}^{\mathrm{c}}\end{array}$ & $\begin{array}{l}\text { 2_A1 } \\
\text { Tom }^{\text {d }}\end{array}$ \\
\hline Samples, $N^{\mathrm{e}}$ & 64 & 105 & 64 & 80 & 161 & 763 & 31 \\
\hline $\mathrm{MLGs}^{\mathrm{f}}$ & 24 & 33 & 15 & 67 & 138 & 269 & 27 \\
\hline eMLG $^{\mathrm{g}}$ & 24.8 & 22.1 & 14.0 & 28.8 & 29.9 & 21.9 & 27.0 \\
\hline HexPh & 0.429 & 0.443 & 0.416 & 0.497 & 0.527 & 0.495 & 0.508 \\
\hline Simpsons $\mathrm{I}^{\mathrm{i}}$ & 0.850 & 0.915 & 0.781 & 0.983 & 0.991 & 0.963 & 0.959 \\
\hline Shannon $\mathrm{I}^{\mathrm{j}}$ & 2.57 & 2.90 & 2.03 & 4.14 & 4.86 & 4.43 & 3.26 \\
\hline
\end{tabular}

a US-1 lineage on tomato.

b US-1 lineage on potato.

c 2_A1 lineage on potato.

d 2_A1 lineage on tomato.

e Number of Phytophthora infestans samples of each clonal genotype from each host.

f Number of distinct multilocus genotypes (MLGs) discriminated.

g Expected number of MLGs (eMLG) after rarefaction (or genetic richness at the largest shared sample size).

h Nei's index of gene diversity defined as the probability that two randomly chosen alleles are different.

i Simpsons's index, showing the probability estimation that two randomly selected genotypes are different.

j Shannon's index, providing genotypic abundance and evenness of the genotypes present. tomato, indicating that this is not a recently adapted subpopulation but, rather, infections by potato-adapted isolates that are weakly aggressive on tomato. However, this high degree of diversity could also be caused by multiple independent adaptation events, or could reflect the fact that 2_A1 has been adapted to tomato for several years; tomato was not sampled in previous studies done since the appearance of 2_A1 in Kenya. No 2_A1 was found on tomato in Uganda, though no samples were collected in eastern Uganda, which borders Kenya. The eastern part of Uganda was the first entry point of 2_A1 into Uganda (Njoroge et al. 2016) and possibly a host shift of 2_A1 from potato to tomato has taken place subsequently.

It will be important in future studies to determine whether 2_A1 occurs on tomato in the other countries. The appearance of the same lineage on both hosts in the region is of epidemiological consequence for either of the scenarios given above because tomato plants are often volunteer plants heavily infested with $P$. infestans and are neither treated with fungicide nor destroyed when growing in close proximity to potato plants. As an illustration of this, the tomato samples used in this study were collected in different potatogrowing areas in the respective countries and mostly from volunteer plants that had no fungicide applied on them. Most of these tomato plants are found in growers' kitchen gardens, where the environment is conducive for both $P$. infestans and its hosts, and where these plants are maintained year-round, potentially providing sources of primary inoculum for epidemics in the growers' fields.

Host specialization within US-1 is still evident in Uganda, Rwanda, and Tanzania, even though the genetic dissimilarity displayed appears minimal. Given the neutrality of the microsatellite markers used in this study, it would appear that host species adaptation has had only a small effect on the overall genetic variability of the two US-1 subpopulations. However, evidence of the differences between the two US-1 subpopulations has been detected using other genetic markers such as effector genes (A. W. Njoroge, M. Ghislain, B. Andersson, E. Magembe, C. Mutai, R. Pelle, J. Yuen, and G. Forbes, unpublished data) and alloenzymes (Vega-Sanchez et al. 2000). Moreover, although these subpopulations appeared to be genetically similar, there were no shared SSR MLGs, further supporting the existence of host specialized subpopulations. No tomato samples from Burundi were available for this study; hence, the lineage of the $P$. infestans on tomato in that country remains unknown.

Implications of population change. To effectively manage late blight, understanding how pathogen populations have changed over time can enhance the effectiveness of current management

TABLE 4. Summary of number of alleles, Simpson's diversity, Nei's gene diversity, evenness of allele distribution, and the standardized Hedricks's $G_{S T}^{\prime}$ in the Phytophthora infestans populations found in different countries on different hosts for the 2017 dataset only

\begin{tabular}{lccccc}
\hline $\begin{array}{l}\text { Simple } \\
\text { sequence } \\
\text { repeat locus }\end{array}$ & Alleles $^{\mathrm{a}}$ & $\begin{array}{c}\text { Simpson's } \\
\text { index }\end{array}$ & $\begin{array}{c}\text { Nei's gene } \\
\text { diversity }\end{array}$ & Evenness & $G^{\prime}{ }_{S T}$ _Hedrick \\
\hline Pi56 & 2 & 0.47 & 0.47 & 0.95 & 0.36 \\
D13 & 22 & 0.71 & 0.71 & 0.52 & 0.75 \\
Pi02 & 7 & 0.67 & 0.67 & 0.83 & 0.30 \\
Pi04 & 5 & 0.51 & 0.51 & 0.95 & 0.02 \\
Pi4B & 3 & 0.22 & 0.22 & 0.58 & 0.35 \\
Pi63 & 8 & 0.66 & 0.66 & 0.98 & 0.50 \\
Pi70 & 6 & 0.60 & 0.60 & 0.83 & 0.31 \\
PiG11 & 22 & 0.70 & 0.70 & 0.61 & 0.30 \\
PinfSSR11 & 3 & 0.52 & 0.52 & 0.91 & 0.12 \\
PinfSSR2 & 4 & 0.27 & 0.27 & 0.55 & 0.30 \\
PinfSSR4 & 14 & 0.74 & 0.74 & 0.72 & 0.77 \\
PinfSSR6 & 6 & 0.57 & 0.57 & 0.83 & 0.47 \\
PinfSSR8 & 4 & 0.66 & 0.66 & 0.94 & 0.46 \\
\hline
\end{tabular}

a Number of microsatellite alleles per locus. Locus D13 and PiG11 have the highest number of alleles while locus PinfSSR4 has the highest Simpson diversity (0.74) and Pi63 has the most evenly distributed alleles (0.98). PinfSSR4 locus reveals the highest ability for population segregation, with a Hendrick's standardized index of 0.77 . 


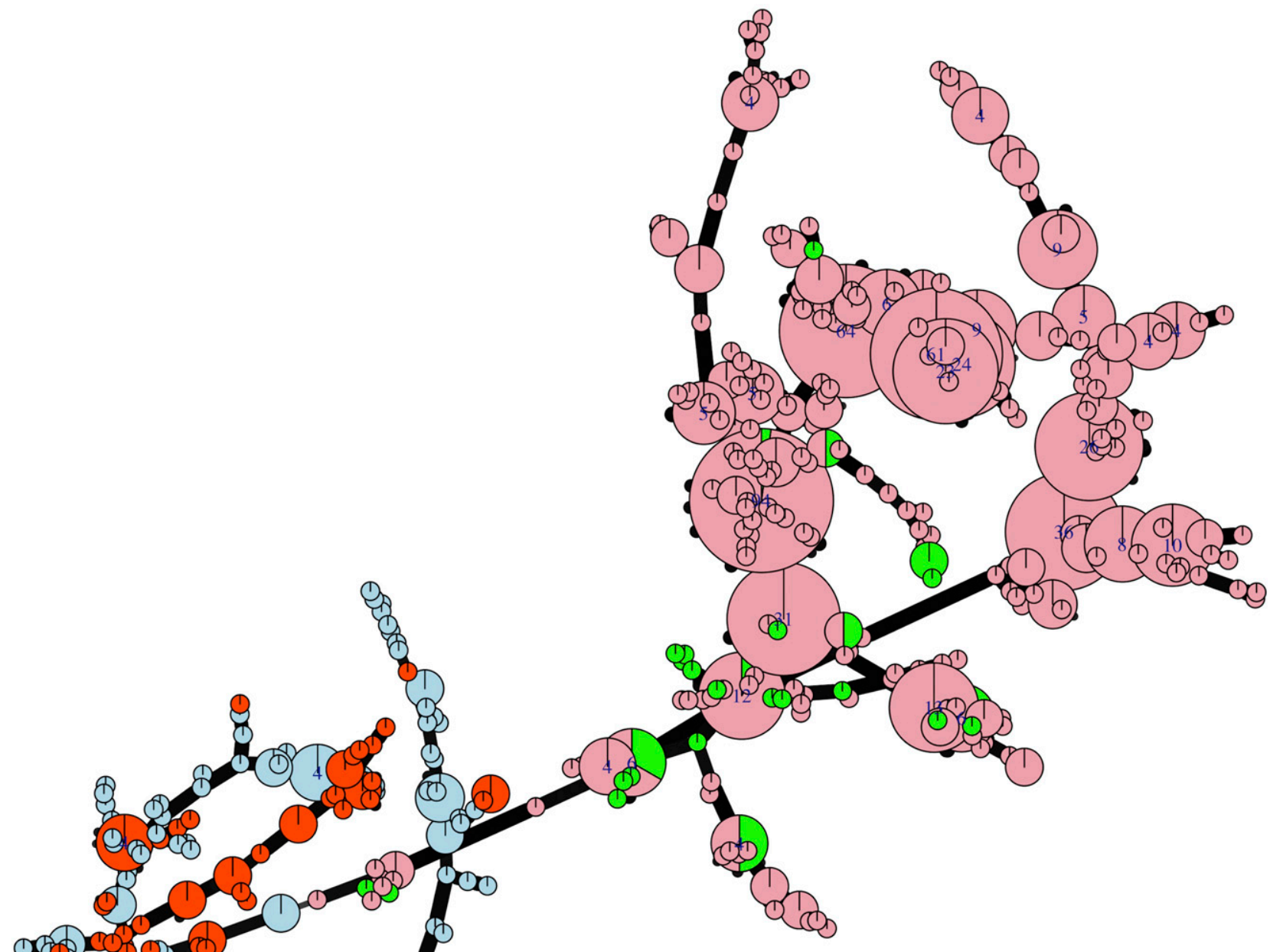

POPULATION
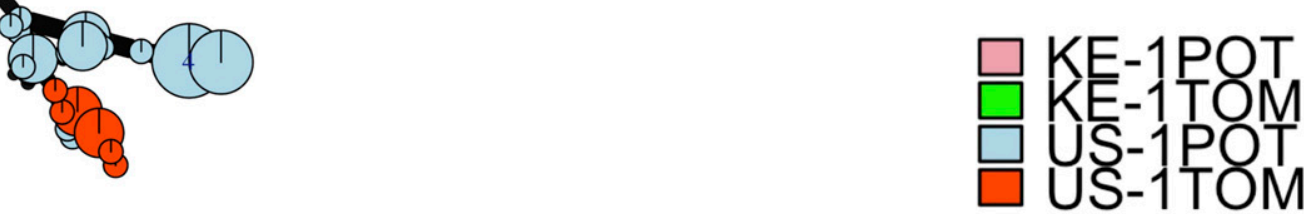

\section{DISTANCE}

Fig. 4. Minimum spanning networks (MSN) for Phytophthora infestans samples from the 2017 dataset grouped according to population "clonal_lineage_host"

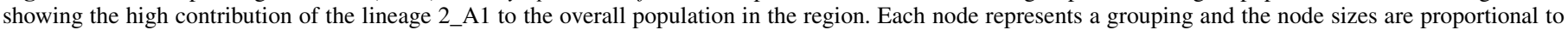

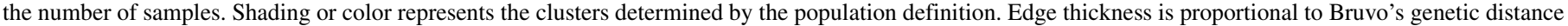

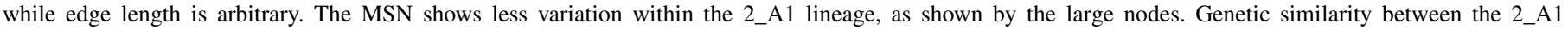

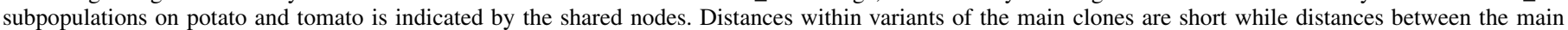

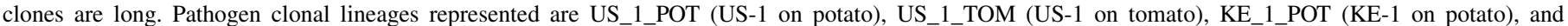
KE_1_TOM (KE-1 on tomato). 
strategies, including host resistance management, fungicide optimization, and the use of integrated pest management tools. In Europe, knowledge of pathogen population changes is used to upgrade highly structured and sophisticated decision support systems from both public and private sectors (Cooke et al. 2011). In EAR and other low income regions, however, such systems do not exist and managing late blight is more of an individual affair, depending on the disease management resources available to a particular farmer.

The results indicating that tomato and potato can serve as alternative hosts in the EAR would argue for a stricter control of garden plants and volunteers, which may serve as sources of initial inoculum. However, these plants are regarded as legitimate sources of food by most small-scale farmers in the region and it is doubtful that they would be willing to remove them.

Population change in $P$. infestans has been associated with the reemergence of strains that are able to overcome modern control techniques such as fungicides with improved efficacy and host resistance (Fry 2008; Kirk et al. 2009). The EAR has had a US-1 population characterized by isolates with high phenylamide insensitivity (Mukalazi et al. 2001; Vega-Sanchez et al. 2000) and it is highly likely that 2_A1 has also developed insensitivity to these products, or it would not have spread so quickly. Farmers in the region have traditionally been able to treat potato with fewer sprays than predicted by simulation modeling and it was

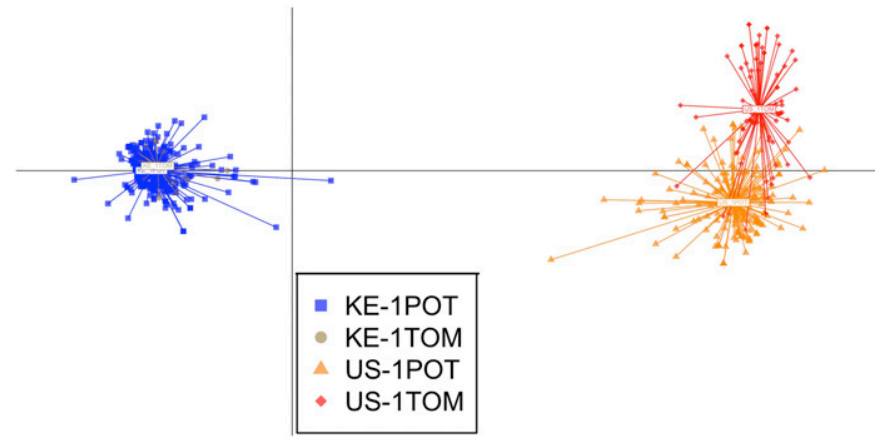

Fig. 5. Discriminant analysis of principal components (DAPC) of the individual samples of the different clonal lineages in the 2017 dataset of Phytophthora infestans samples using 13 principal component analyses showing dissimilarity in the clustering of tomato and potato US-1 subpopulations and more similarity in the 2_A1 subpopulations on the two hosts. Groups are represented by shade or symbol as well as by inertia ellipses. Each point represents a single sample grouped by population "clonal_lineage_host". Pathogen clonal lineages represented are US_1_POT (US-1 on potato), US_1_TOM (US-1 on tomato), KE_1_POT (KE-1 on potato), and KE_1_TOM (KE-1 on tomato).

TABLE 5. Summary of results of analysis of molecular variance conducted on clone-corrected datasets of Phytophthora infestans, indicating the percentage of genetic variation attributable to population level differences of 2_A1 clonal lineage for regions (2014 dataset) and countries (2017 full dataset) and, between potato-and tomato-adapted US-1 clonal lineages

\begin{tabular}{|c|c|c|c|c|c|}
\hline \multirow[b]{2}{*}{ Lineage } & \multirow[b]{2}{*}{$\begin{array}{l}\text { Source of } \\
\text { variation }\end{array}$} & \multicolumn{2}{|c|}{2014 dataset } & \multicolumn{2}{|c|}{2017 dataset } \\
\hline & & $\begin{array}{l}\text { Variance of } \\
\text { total }(\%)\end{array}$ & $\phi^{* a}$ & $\begin{array}{c}\text { Variance of } \\
\text { total }(\%)\end{array}$ & $\phi^{* \mathrm{a}}$ \\
\hline \multirow[t]{3}{*}{ 2_A1 } & $\begin{array}{l}\text { Between regions } \\
\text { or countries }\end{array}$ & 4 & $0.04^{\mathrm{b}}$ & 23 & $0.24^{b}$ \\
\hline & Within countries & 96 & $\ldots$ & 77 & $\ldots$ \\
\hline & Total & 100 & $\ldots$ & 100 & $\ldots$ \\
\hline \multirow[t]{3}{*}{ US-1 } & Between hosts & 7 & $0.07^{\mathrm{c}}$ & 13 & $0.13^{\mathrm{c}}$ \\
\hline & Within hosts & 93 & $\ldots$ & 87 & $\ldots$ \\
\hline & Total & 100 & $\ldots$ & 100 & $\ldots$ \\
\hline
\end{tabular}

a Population differentiation statistics where higher values represent a higher amount of differentiation.

b The $\phi^{*}$ includes contribution of the potato 2_A1KenyaRef (reference samples) to the overall variance.

c The $\phi^{*}$ does not include the 2_A1KenyaRef reference samples. hypothesized that this was due to the reduced pathogenicity of US-1 (Forbes et al. 2009). If this was the case, one could expect that farmers in the EAR will now need to adapt their spray regimes to a new pathogen population that is more difficult to manage. Some growers, particularly in Kenya, recently complained of an increase of severe stem blight, which is difficult to manage because fungicides give poor coverage of stems when the canopy is full. This results in the disease continuing to spread and kill the crop rendering the efforts to use the chemical control ineffective. Although there is no evidence to indicate that this problem is a direct result of the presence of 2_A1, increased stem infections have previously been associated with pathogen population change (Cooke et al. 2011).

When resistant cultivars are released in late-blight-prone areas, pathogen monitoring for factors that could help overcome resistance durability would aid in host resistance deployment. Consequently, the occurrence of the same pathogen strains in different countries within a region means the breeding programs and growers can use similar host cultivars or at least know what resistance genes are appropriate for their region. The International Potato Center and the Ugandan authorities have developed cultivars with cassettes of known resistance genes for release in Uganda and eventually other countries in the region. Monitoring of effector evolution in the pathogen population would be an important tool for increasing the durability of this resistance. Use of appropriate resistance genes and effective fungicides are some of the measures that can lessen the devastating effects of new pathogen strains, despite the fact that new management strategies are difficult to implement in grower communities (Fry 2008; Gachango et al. 2012).

It will also be important to ensure that any population surveillance in the region is coordinated and uses standardized procedures. Microsatellite genotyping provides a fast and reliable tool to track pathogen changes and compare the findings with other networks in Europe, Asia, and the Americas but these meta-analyses can only be done if data are produced using standardized procedures.

\section{LITERATURE CITED}

Baldwin, B. 1956. News from Africa. Uganda. Commonwealth PhytopathologyNews 2:25-29.

Berkeley, M. J. 1846. Observations, botanical and physiological, on the potato murrain. J. Hortic. Soc. Lond. 1:9-34.

Birch, P. R., and Cooke, D. E. 2013. Genomics: The early days of late blight. eLife 2:e0954.

Blandón-Díaz, J. U., Widmark, A.-K., Hannukkala, A., Andersson, B., Högberg, N., and Yuen, J. E. 2012. Phenotypic variation within a clonal lineage of Phytophthora infestans infecting both tomato and potato in Nicaragua. Phytopathology 102:323-330.

Bourke, P. M. A. 1964. Emergence of potato blight, 1843-46. Nature 203: 805-808.

Brurberg, M. B., Elameen, A., Le, V. H., Naerstad, R., Hermansen, A., Lehtinen, A., Hannukkala, A., Nielsen, B., Hansen, J., Andersson, B., and Yuen, J. 2011. Genetic analysis of Phytophthora infestans populations in the Nordic European countries reveals high genetic variability. Fungal Biol. 115:335-342.

Bruvo, R., Michiels, N. K., D’Souza, T. G., and Schulenburg, H. 2004. A simple method for the calculation of microsatellite genotype distances irrespective of ploidy level. Mol. Ecol. 13:2101-2106.

Cardenas, M., Danies, G., Tabima, J., Bernal, A., and Restrepo, S. 2012. Phytophthora infestans population structure: A worldwide scale. Acta Biol. Colomb. 17:227-240.

Clark, L. V., and Jasieniuk, M. 2011. POLYSAT: An R package for polyploid microsatellite analysis. Mol. Ecol. Resour. 11:562-566.

Cooke, D. E. L., Young, V., Birch, P. R. J., Toth, R., Gourlay, F., Day, J. P., Carnegie, S. F., and Duncan, J. M. 2003. Phenotypic and genotypic diversity of Phytophthora infestans populations in Scotland 1995-97. Plant Pathol. 52:181-192.

Cooke, L. R., Schepers, H. T. A. M., Hermansen, A., Bain, R. A., Bradshaw, N. J., Ritchie, F., Shaw, D. S., Evenhuis, A., Kessel, G. J. T., Wander, J. G. N., Andersson, B., Hansen, J. G., Hannukkala, A., Nærstad, R., and Nielsen, B. J. 2011. Epidemiology and integrated control of potato late blight in Europe. Potato Res. 54:183-222.

Cox, A. E., and Large, E. C. 1960. Potato late blight epidemics throughout the world. U.S. Dep. Agric. Handb. 174. U.S. Government Printing Office, Washington, DC. 
Day, J. P., and Shattock, R. C. 1997. Aggressiveness and other factors relating to displacement of populations of Phytophthora infestans in England and Wales. Eur. J. Plant Pathol. 103:379-391.

Day, J. P., Wattier, R. A. M., Shaw, D. S., and Shattock, R. C. 2004. Phenotypic and genotypic diversity in Phytophthora infestans on potato in Great Britain, 1995-98. Plant Pathol. 53:303-315.

Delgado, R. A., Monteros-Altamirano, A. R., Li, Y., Visser, R. G. F., van der Lee, T. A. J., and Vosman, B. 2013. Large subclonal variation in Phytophthora infestans populations associated with Ecuadorian potato landraces. Plant Pathol. 62:1081-1088.

Dray, S., and Dufour, A. B. 2007. The ade4 package: Implementing the duality diagram for ecologists. J. Stat. Softw. 22:1-20.

Flier, W. G., Grünwald, N. J., Kroon, L. P. N. M., Sturbaum, A. K., van den Bosch, T. B. M., Garay-Serrano, E., Lozoya-Saldana, H., Fry, W. E., and Turkensteen, L. J. 2003. The population structure of Phytophthora infestans from the Toluca Valley of Central Mexico suggests genetic differentiation between populations from cultivated potato and wild Solanum spp. Phytopathology 93:382-390.

Forbes, G. A., Goodwin, S. B., Drenth, A., Oyarzún, P., Ordoñez, M. E., and Fry, W. E. 1998. A global marker database for Phytophthora infestans. Plant Dis. 82:811-818.

Forbes, G. A., Shtienberg, D., and Mizubuti, E. 2009. Plant disease epidemiology and disease management - has theory had an impact on practice? Pages 351-368 in: Integrated Pest Management: Innovation-Development Process. R. Peshin and A. K. Dhawan, eds. Springer Netherlands, New York.

Fry, W. 2008. Phytophthora infestans: The plant and R gene destroyer. Mol. Plant Pathol. 9:385-402.

Gachango, E., Kirk, W. W., and Schafer, R. 2012. Effects of in-season cropprotection combined with postharvest applied fungicide on suppression of potato storage diseases caused by oomycete pathogens. Crop Prot. 41:42-48.

Gómez-Alpizar, L., Carbone, I., and Ristaino, J. B. 2007. An Andean origin of Phytophthora infestans inferred from mitochondrial and nuclear gene genealogies. Proc. Natl. Acad. Sci. USA 104:3306-3311.

Goodwin, S. B. 1997. The population genetics of Phytophthora. Phytopathology 87:462-473

Goodwin, S. B., Cohen, B. A., and Fry, W. E. 1994. Panglobal distribution of a single clonal lineage of the Irish potato famine fungus. Proc. Natl. Acad. Sci. USA 91:11591-11595.

Goss, E. M., Tabima, J. F., Cooke, D. E., Restrepo, S., Fry, W. E., Forbes, G. A., Fieland, V. J., Cardenas, M., and Grünwald, N. J. 2014. The Irish potato famine pathogen Phytophthora infestans originated in central Mexico rather than the Andes. Proc. Natl. Acad. Sci. USA 111:8791-8796.

Griffith, G. W., and Shaw, D. S. 1998. Polymorphisms in Phytophthora infestans: Four mitochondrial haplotypes are detected after PCR amplification of DNA from pure cultures or from host lesions. Appl. Environ. Microbiol. 64:4007-4014.

Grünwald, N. J. 2012. Genome sequences of Phytophthora enable translational plant disease management and accelerate research. Can. J. Plant Pathol. 34:13-19.

Grünwald, N. J., and Flier, W. G. 2005. The biology of Phytophthora infestans at its center of origin. Annu. Rev. Phytopathol. 43:171-190.

Hedrick, P. W. 1999. Perspective: Highly variable loci and their interpretation in evolution and conservation. Evolution 53:313-318.

Hedrick, P. W. 2005. A standardized genetic differentiation measure. Evolution 59:1633-1638.

Hohl, H. R. 1998. Page 40 in: On the A2 Hunting Safari in Eastern Africa: Low Levels of Oospores in Mating and High Levels of Oospores in Selfing. International Potato Centre (CIP) Sub-Saharan Africa, Nairobi, Kenya.

Hurlbert, S. H. 1971. The nonconcept of species diversity: A critique and alternative parameters. Ecology 52:577-586.

Jombart, T., and Ahmed, I. 2011. adegenet 1.3-1: New tools for the analysis of genome-wide SNP data. Bioinformatics 27:3070-3071.

Jombart, T., Devillard, S., and Balloux, F. 2010. Discriminant analysis of principal components: A new method for the analysis of genetically structured populations. BMC Genet. 11:94.

Kamvar, Z. N., Tabima, J. F., and Grünwald, N. J. 2014. Poppr: An R package for genetic analysis of populations with clonal, partially clonal, and/or sexual reproduction. PeerJ 2:e281.

Kirk, W. W., Abu-El Samen, F., Tumbalam, P., Wharton, P., Douches, D., Thill, C. A., and Thompson, A. 2009. Impact of different US genotypes of Phytophthora infestans on potato seed tuber rot and plant emergence in a range of cultivars and advanced breeding lines. Potato Res. 52:121-140.

Knapova, G., and Gisi, U. 2002. Phenotypic and genotypic structure of Phytophthora infestans populations on potato and tomato in France and Switzerland. Plant Pathol. 51:641-653.

Lees, A. K., Wattier, R., Shaw, D. S., Sullivan, L., Williams, N. A., and Cooke, D. E. L. 2006. Novel microsatellite markers for the analysis of Phytophthora infestans populations. Plant Pathol. 55:311-319.

Li, Y., Cooke, D. E., Jacobsen, E., and van der Lee, T. 2013. Efficient multiplex simple sequence repeat genotyping of the oomycete plant pathogen Phytophthora infestans. J. Microbiol. Methods 92:316-322.
Li, Y., Govers, F., Mendes, O., Testa, A., Jacobsen, E., Huang, S. W., and van der Lee, T. A. J. 2010. A new set of highly informative SSR markers for Phytophthora infestans population analysis assembled into an efficient multiplex. Mol. Ecol. Resour. 10:1098-1105.

May, K. J., and Ristaino, J. B. 2004. Identity of the mtDNA haplotypes of Phytophthora infestans in historical specimens from the Irish potato famine. Mycol. Res. 108:471-479.

Mayton, H., Aylor, D. E., and Fry, W. E. 2000. Quantitative assessment of inoculum sources of potato late blight. (Abstr.) Phytopathology 90:S50.

Meirmans, P. G., and Hedrick, P. W. 2011. Assessing population structure: FST and related measures. Mol. Ecol. Resour. 11:5-18.

Mukalazi, J., Adipala, E., Sengooba, T., Hakiza, J. J., Olanya, M., and Kidanemariam, H. M. 2001. Metalaxyl resistance, mating type and pathogenicity of Phytophthora infestans in Uganda. Crop Prot. 20:379-388.

Natrass, R. M. 1944. Potato blight. East Afr. Agric. J. 10:18-21.

Niederhauser, J. S. 1991. The Potato Association of America and international cooperation 1916-1991. Am. Potato J. 68:237-239.

Njoroge, A. W., Andersson, B., Yuen, J. E., and Forbes, G. A. 2019. Greater aggressiveness in the 2_A1 lineage of Phytophthora infestans may partially explain its rapid displacement of the US-1 lineage in east Africa. Plant Pathol.

Njoroge, A. W., Tusiime, G., Forbes, G. A., and Yuen, J. E. 2016. Displacement of US-1 clonal lineage by a new lineage of Phytophthora infestans on potato in Kenya and Uganda. Plant Pathol. 65:587-592.

Oyarzun, P. J., Pozo, A., Ordoñez, M. E., Doucett, K., and Forbes, G. A. 1998. Host specificity of Phytophthora infestans on tomato and potato in Ecuador. Phytopathology 88:265-271.

Pule, B. B., Meitz, J. C., Thompson, A. H., Linde, C. C., Fry, W. E., Langenhoven, S. D., Meyers, K. L., Kandolo, D. S., van Rij, N. C., and McLeod, A. 2013. Phytophthora infestans populations in central, eastern and southern African countries consist of two major clonal lineages. Plant Pathol. 62:154-165.

Saville, A. C., Martin, M. D., and Ristaino, J. B. 2016. Historic late blight outbreaks caused by a widespread dominant lineage of Phytophthora infestans Mont. de Bary. PLoS One 11:e0168381.

Schiessendoppler, E., and Molnar, O. 2002. Characterization of Phytophthora infestans populations in Sub-Saharan Africa as a basis for simulation modeling and integrated disease management. Page 140 in: Late Blight: Managing the Global Threat, Proc. Global Initiative on Late Blight Conf. C. Lizárraga, ed. International Potato Center, Lima, Peru and Hamburg, Germany.

Shannon, C. E. 2001. A mathematical theory of communication. ACM SIGMOBILE Mob. Comput. Commun. Rev. 5:3-55.

Shattock, R. C., Tooley, P. W., and Fry, W. E. 1986a. Genetics of Phytophthora infestans: Characterization of single-oospore cultures from A1 isolates induced to self by intraspecific stimulation. Phytopathology 76:407-410.

Shattock, R. C., Tooley, P. W., and Fry, W. E. 1986b. Genetics of Phytophthora infestans: Determination of recombination, segregation, and selfing by isozyme analysis. Phytopathology 76:410-413.

Shimelash, D., Hussien, T., Fininsa, C., Forbes, G., and Yuen, J. 2016. Mitochondrial DNA assessment of Phytophthora infestans isolates from potato and tomato in Ethiopia reveals unexpected diversity. Curr. Genet. 62:657-667.

Simpson, E. H. 1949. Measurement of diversity. Nature 163:688.

Sjöholm, L., Andersson, B., Högberg, N., Widmark, A.-K., and Yuen, J. 2013. Genotypic diversity and migration patterns of Phytophthora infestans in the Nordic countries. Fungal Biol. 117:722-730.

Tooley, P. W., Sweigard, J. A., and Fry, W. E. 1985. Virulence, aggressiveness, and fitness of Phytophthora infestans isolates from sexual and asexual populations. (Abstr.) Phytopathology 75:1319.

van Loon, K. D. 2007. The seed potato market. Pages 45-51 in: Potato Biology and Biotechnology. D. Vreugdenhil, ed., Oxford.

Vega-Sanchez, M. E., Erselius, L. J., Rodriguez, A. M., Bastidas, O., Hohl, H. R., Ojiambo, P. S., Mukalazi, J., Vermeulen, T., Fry, W. E., and Forbes, G. A. 2000. Host adaptation to potato and tomato within the US-1 clonal lineage of Phytophthora infestans in Uganda and Kenya. Plant Pathol. 49:531-539.

Wallace, G. B., and Wallace, M. M. 1945. Tomato Blight. East Afr. Agric. J. 10:181-182.

Weir, B.S., and Cockerham, C.C. 1984. Estimating F-statistics for the analysis of population structure. Evolution 38:1358-1370.

Were, H. K., Kabira, J. N., Kinyua, Z. M., Olubayo, F. M., Karinga, J. K., Aura, J., Lees, A. K., Cowan, G. H., and Torrance, L. 2013. Occurrence and distribution of potato pests and diseases in Kenya. Potato Res. 56: 325-342.

Yoshida, K., Schuenemann, V. J., Cano, L. M., Pais, M., Mishra, B., Sharma, R., Lanz, C., Martin, F. N., Kamoun, S., Krause, J., Thines, M., Weigel, D., and Burbano, H. A. 2013. The rise and fall of the Phytophthora infestans lineage that triggered the Irish potato famine. eLife 2:e00731.

Zadoks, J. 2008. The potato murrain on the European continent and the revolutions of 1848. Potato Res. 51:5-45. 